\title{
Optimizing Performance of Porcelain Insulators: How does Particle Size Influence Dielectric and Mechanical Strengths?
}

\author{
Temitope Ologunwa ${ }^{1}$, Tolulope Akinbogun ${ }^{1}$, Robert Frischer ${ }^{2}$, Isah Kashim ${ }^{1}$, Kamil Kuca ${ }^{2}$, \\ Ondrej Krejcar ${ }^{2, *}$, Oluwaseun Fadeyi ${ }^{2,3}$ \\ Industrial Design Department, Federal University of Technology, P.M.B 704, Akure, Ondo State, Nigeria \\ Center for Basic and Applied Research, Faculty of Informatics and Management, University of Hradec Kralove, Rokitanskeho 62, Hradec Kralove, \\ 500 03, Czech Republic \\ Department of Geology, Faculty of Geography and Geoscience, University of Trier, Universitätsring 15, 54296 Trier, Germany
}

\begin{abstract}
Porcelain insulators are mostly created from the combination of the particles of Clay, Silica, Kaolin, and Feldspar. This implies that different particle sizes contribute to the insulating properties of the materials. In this paper, we attempt to create a set of model porcelain materials by critically analysing the particle sizes that are most likely to yield the best insulator results. Materials sourced from Edo State, Nigeria were processed to produce Porcelain insulator samples. For each of the component minerals, a $65 \mathrm{~g}$ mass was compacted and pressed at 500 Psi (3.4 KN) into a steel cylindrical mould via hydraulic press, this was closely followed by firing at $1200^{\circ} \mathrm{C}$. Porosity, bulk density, insulation volume resistivity, as well as dielectric strength, and their relationship with particle sizes were evaluated. Results obtained showed that porosity of the Porcelain materials shared a direct relation with particle sizes, while the bulk density showed an inverse relationship. It was also observed that the $150 \mu \mathrm{m}$ particles yielded the most effective insulators, given higher insulation volume resistivity and dielectric strength. Altering particle size from $150 \mu \mathrm{m}$ tends to lower the insulation volume resistivity and dielectric strength.
\end{abstract}

Keywords: Particle Size, Porcelain Insulator, Porosity, Bulk Density, Dielectric Strength

\section{Introduction}

Porcelain materials are a group of ceramic that yield high quality lustered substances when fired at very high temperatures. These products possess translucent behaviours with low porosity. Porcelain in itself is a vitrified fine grained ceramic whiteware body that can either be glazed or unglazed [1]. It is composed mainly of clay which contributes to its plastic character; feldspar which acts as fluxing agent (lowers melting point of the material under the influence of heat). Geologically, Feldspars have been described as minerals with symmetry, which are either monoclinic or triclinic in nature, and may possibly aid several slip systems, based on the direction from which they are stressed [2]. The mineral occurs largely within the Earth's crust [3], so that they dissolve to impact the behaviour of Silica and Alumina, as well as a number of Alkaline Earth metals found within the Biosphere, in naturally existing water bodies, and in soils [4]. Feldspars are technically the minerals with the highest abundance in Porcelain materials. Together with Kaolin and Silica, as well as Clay, these materials are moulded into what is known as "Porcelain Insulators" [5]. According to Bundy and Ishley [6], Kaolin is useful as mineral filler and is able to provide a glossy, bright and smooth outlook on materials with which it is composed. As such, the mineral has found a number of industrial usages over time [7]. One crucial use of Feldspars and Kaolin in addition to Silica and Clay is in the design of Porcelain insulators. Silica which helps to

* Corresponding author: Ondrej Krejcar, E-mail address: ondrej.krejcar@uhk.cz 
maintain the shape of the formed products during firing [8]. The toughness, strength and translucency of Porcelain are crucial features that has so far resulted in the material gaining wide range of application, especially as household, laboratory and industrial materials. Porcelain materials also find suitable application as insulators in electrical units, given their high electrical, mechanical and thermal stability in harsh environments [9]. Without insulating bodies, it becomes difficult for household, industries and all other power consumption outlets to connect to national power grids. In the early days of household electricity wiring, Tod [10] explained that wood was mainly adopted as insulators. Nevertheless, excessive incidents of burnt homes resulting from short circuit situations was one of the reasons for early preference of Porcelain insulators. Burning homes meant that insurance companies frowned against the use of wood, causing many individuals to opt for Porcelain which was then very expensive in the United States around 1890 This situation drove a series of patents in Porcelain design with Pass and Seymour patenting a "doublewire cleat" Porcelain [9-10].

There are several insulator types in today's markets. However, a popular misrepresentation of insulator types is the confusion with insulation materials. While Insulator types include; pin, post, shackle, etc., insulator materials are those substances used in designing the insulators such as glass, porcelain etc. As such, there is a clear distinction between types of insulators and their material make-up. According to Sachidananda [11], a large number of insulator types exist in literature. Nevertheless, pin, suspension, strain, and shackle insulator types are the most common [12]. Shackle or spool insulators like stay insulator are also used in low voltage transmission lines [13]. They can be vertically or horizontally arranged. A shackle insulator is designed with a tapered hole that helps in even distribution of insulator load, so as to guide against insulator breakage from heavy load. A soft wire is used to bind the conductor to the unit in shackle insulators.

Modern day materials focus on certain properties for selection as insulators. These properties include: thermal conductivity, a measure of the ease of allowance of heat within a material via conduction, which has a unit of $\lambda$ (which denotes lambda) [14]. Thermal resistance is also a crucial property, as it links thermal conductivity and width of a material, so that it measured in resistance per unit area $\left(\mathrm{m}^{2} \mathrm{~K} / \mathrm{W}\right)$. This implies that a material that has a very low thickness will allow huge flow of heat. As such, thermal resistance must be very high for a material to be referred to as a good insulating unit [15]. As such, density is also a very important feature to look out for in order to select an insulator [16]. The so-called thermal diffusivity in itself may also be considered important. This is because it is a material's ability to conduct heat energy as a function of how it stores up heat.

Dielectric and mechanical strengths are the two most crucial properties of Porcelain bodies in electrical application and some reasons the materials became very popular [17]. Crystalline formation of mullite and particles size are considered as basic factors that contribute to production of highstrength electrical Porcelain insulators [17]. Particle size and consistency of the properties of the starting powders are critical requirement to achieving high voltage insulators [10]. Particle size tends to impact brawn, fluidity, malleability, abrasiveness, ease of dispersion, and colour of materials [18]. Large particle sizes allow the formation of pores unlike the smaller ones that tend to eradicate pores. Smaller pore sizes improve bulk density, and aids how a material absorbs water. Processing a material to low micron particle sizes tend to strengthen the insulator produced in the fabrication processes.

Research on Porcelain insulators are not entirely new. In fact, these insulators became popular when potters started designing telegraph insulators in the 1850s. During the time, Porcelain insulators were designed without threads, with only a few pieces produced in comparison to glass insulators [19]. Examples of early Porcelain insulator types include; porcelain type of "Slash top" (U-988) and "Teapot" (U-990), "Elliot" flint insulators (U-980 and U-981) as well as the Bennington insulators designed with special glazing (U-982 and U-983) [19]. Just like glass insulators, Porcelain insulators can either be described using Uni or Multi-part numbers. Uniparts refer to multiple Porcelain pieces that have undergone binding by glazing otherwise known as glaze welding, they also describe single Porcelain pieces. On the other hand, Multipart Porcelain insulators have more than one cemented sections [19]. In the earlier years of the production of Porcelain insulators, the materials received 
huge interest, coming in varieties of colour. More recently, the cost of glass insulators has further increased interest in Porcelain-based insulators [20]. Another unique feature of Porcelain insulators is the manufacturers' label which often bears the name of the manufacturer and date of production of the insulator in some cases [19].

A 1942 study by Nature [21] noted that while ceramics materials draw their plastic nature from ball and china clays, physic-mechanical attributes of materials produced therefore are dependent upon the nature of crystals (for glass) and particle sizes for materials such as Porcelain. While Porcelain insulators are still extensively used nowadays, these materials have been researched to have specific short-comings vastly documented in literature. For instance, one of the earliest studies to document contamination of Porcelain surface by [22] posited that air-borne particles and moisture films may impact the surface of Porcelain materials used outdoors. Luo et al [23] discussed possible pin and iron cap corrosion of Porcelain materials in a research domiciled in China, [24] also studied the growth of biota acting as contaminants on Porcelain surface, [25] cited excessive cost accrued in replacing Porcelain materials due to deterioration, especially when they have been used in large outdoor electrical installation projects. As a result of the many challenges of Porcelain insulators,
Luo et al. [23] as well as McAfee [24] pointed to several ongoing researches aimed at replacing both glass and Porcelain insulator types with polymeric materials and a number of other materials (Table 1).

While there are studies aimed at phasing out Porcelain insulators, several others abound to optimize Porcelain insulators and make them perform even better. As such, the current study has the objective of evaluating the effect of particles size on the dielectric strength of insulator, an act that may possibly help manufacturers to optimize production patterns. It is aimed at determining specific particle sizes that are detrimental to high dielectric strength and mechanical property at producing these insulators.

The remainder of this paper is arranged thus; Section 1 details some existing insulator types, explaining the merits and demerits of each of them. The section further describes some of the many challenges of Porcelain, as well as some other insulators earmarked to act as replacements for Porcelain materials. In furtherance, specific Porcelain patents holders and assignees are described, in addition to the need for optimization of Porcelain materials in terms of factors that may influence dielectric and mechanical strengths. Section 2 describes experimental procedures for the current study detailing how a typical Porcelain insulator is crafted. In section 3, results of the study which

Table 1: Characteristics of some insulating materials [14]

\begin{tabular}{|c|c|c|c|c|c|c|}
\hline Insulator material & $\begin{array}{c}\text { Thermal } \\
\text { conductivity/ } \lambda \\
\text { (lambda) } \\
\text { [W/m.K] }\end{array}$ & $\begin{array}{c}\text { Thermal } \\
\text { resistance at } \\
100 \mathrm{~mm} \\
{\left[\mathrm{~K} \cdot \mathrm{m}^{2} / \mathrm{W}\right]}\end{array}$ & $\begin{array}{c}\text { Specific Heat } \\
\text { Capacity } \\
\text { [J/kg.K] }\end{array}$ & $\begin{array}{l}\text { Density } \\
{\left[\mathrm{kg} / \mathrm{m}^{3}\right]}\end{array}$ & $\begin{array}{c}\text { Thermal } \\
\text { diffusivity } \\
{\left[\mathrm{m}^{2} / \mathrm{s}\right]}\end{array}$ & $\begin{array}{c}\text { Vapour } \\
\text { permeable }\end{array}$ \\
\hline Aerogel [13][16] & 0.014 & 3.8 for $50 \mathrm{~mm}$ & 1000 & 150 & - & Yes \\
\hline Wood fibre (Rigid) [26] & 0.038 & 2.5 & 2100 & 160 & $\mathrm{n} / \mathrm{a}$ & Yes \\
\hline Wood fibre (Flexible) [26] & 0.038 & 2.6 & 2100 & 50 & $\mathrm{n} / \mathrm{a}$ & Yes \\
\hline Extruded polystyrene & $0.033-0.035$ & 3 & - & $20-40$ & - & No \\
\hline $\begin{array}{c}\text { Brown-sprayed cellulose } \\
\text { [27] }\end{array}$ & $\begin{array}{c}0.035 \text { (lofts) } \\
0.038-0.040 \\
\text { (walls). }\end{array}$ & 2.632 & 2020 & $27-65$ & $\mathrm{n} / \mathrm{a}$ & Yes \\
\hline Expanded polystyrene & $0.034-0.038$ & 3.52 & 1300 & 30 & - & No \\
\hline Wool [28] & 0.038 & 2.63 & 1800 & 23 & $\mathrm{n} / \mathrm{a}$ & Yes \\
\hline $\begin{array}{l}\text { Polyisocyanurate/ } \\
\text { Polyurethane foam }\end{array}$ & $0.023-0.026$ & 4.50 & $\mathrm{n} / \mathrm{a}$ & $30-40$ & $\mathrm{n} / \mathrm{a}$ & No \\
\hline Hemp [29] & $0.039-0.040$ & 2.5 & $1800-2300$ & $25-38$ & $\mathrm{n} / \mathrm{a}$ & Yes \\
\hline Phenolic foam & 0.020 & 5.00 & $\mathrm{n} / \mathrm{a}$ & 35 & $\mathrm{n} / \mathrm{a}$ & No \\
\hline Hempcrete & 0.06 & 1.429 & $1500-1700$ & 275 & $1.5 \times 10^{-7}$ & Yes \\
\hline $\begin{array}{c}\text { Icynene H2FoamLite / LD- } \\
\text { C-50 }\end{array}$ & 0.039 & $\mathrm{n} / \mathrm{a}$ & $\mathrm{n} / \mathrm{a}$ & $7.5-8.3$ & $\mathrm{n} / \mathrm{a}$ & Yes \\
\hline Cellular glass & 0.041 & $\mathrm{n} / \mathrm{a}$ & 1000 & 115 & $4.2 \times 10^{-7}$ & No \\
\hline Rock mineral wool & $0.032-0.044$ & $2.70-2.85$ & $\mathrm{n} / \mathrm{a}$ & $\mathrm{n} / \mathrm{a}$ & $\mathrm{n} / \mathrm{a}$ & Yes \\
\hline Straw & 0.08 & $\begin{array}{l}4.37 \text { for } \\
350 \mathrm{~mm}\end{array}$ & - & $110-130$ & $\mathrm{n} / \mathrm{a}$ & Yes \\
\hline Glass mineral wool & 0.035 & 2.85 & 1030 & Circa 20 & 0.0000016 & Yes \\
\hline
\end{tabular}


compares how different particle sizes influence the strength of Porcelain insulators is discussed. Lastly, section 4, the concluding section notes the importance of a study of this nature, as well as its shortcomings. The section further makes a case for future research that tends to work towards optimizing Porcelain insulators.

\section{Aim, Materials and Experimental Procedures}

The objective of the current study is to optimize the production and function of Porcelain insulators that will be manufactured in the near future. This is done by specifically trying to understand the effect of particle size on dielectric and mechanical strength of Porcelain insulators. As experimental materials, the study gathered Ball Clay and Kaolin sourced from Aforwa in Edo State, Nigeria, as well as Feldspar and Quartz from Okpella, also in Edo State. Selection choice for these materials is based on their suitability for ceramic applications. Table 2 summarizes the mineralogical compositions of each of the materials. The materials were prepared for XRD analysis using a backloading preparation method. They were analysed with a PANalytical Empyrean diffractometer with PIXcel detector and fixed slits with Fe filtered Co-Ka radiation. The phases were identified using X'PertHighscore plus software. All samples were bagged and transported to the laboratory for further processing. Clays in form of lumps were broken into smaller sizes so that the materials take even lesser time to soak prior to sieving. Feldspar and silica grains were also soaked, so that all materials were made ready for removal of impurities from the materials via sieving. Following the sieving process, each material was allowed to settle down for approximately 24 hours, this provides for decantation, bagging and subsequent sun-drying for two weeks. The materials were then pulverized into powder.

\subsection{Sample Preparation}

In the determination of particle sizes of the processed materials, Endecott test sieve shaker (Series number 11381) with set of Tyler sieves of British Standard was adopted for use. This method helps to conduct particle size test analysis on the processed materials, and done to determine the bulk particle size present in the materials. This way, a relatively broad particle size spectrum was analysed quickly and in a reliable manner. A $250 \mathrm{~g}$ (initial weight) of each material was placed in an Endecott test sieve shaker with set of Tyler sieves to sift the materials for ten minutes. Subsequently, materials retained on each mesh sieves were re-weighed to determine the weight of materials retained on the mesh screen. The weight retained alongside the initial weight was used to calculate the percentage of retained and passing sizes of the material. This procedure was repeated for the remaining three raw materials. Results of the sieve analysis are presented in table 3. The results indicate that all the materials can be classified as sand (i.e., particle size between the range of $6 \mu \mathrm{m}$ and $200 \mu \mathrm{m}$ ). Hence, the materials were disaggregated into three different sand particle sizes $75 \mu \mathrm{m}, 150 \mu \mathrm{m}$ and $300 \mu \mathrm{m}$ representing fine, medium, and course types of sands respectively in other to examine the effect of the particle sizes on the electrical properties of porcelain insulator. Given the basic make-up of Porcelain; Kaolin, Feldspar and Silica. There is a possibility to vary the percentage composition of each of this Porcelain composition in the formulation a new Porcelain based insulator.

Studies like those of Merga et al. [5] and Olupot et al. [29] have previously suggested Porcelain composition formulation suitable for the production of a Porcelain type useful in electrical applications. As such, the current study did adopt body sample

Table 2: Mineralogical composition of raw materials for the study

\begin{tabular}{ccccc}
\hline Mineralogical & Clay [Wt. \%] & Kaolin [Wt. \%] & Silica [Wt. \%] & Feldspar [Wt. \%] \\
\hline Quartz & 43.18 & 21.99 & 95.29 & 41.71 \\
\hline Kaolinite & 53.11 & 75.35 & 4.71 & - \\
\hline Anatse & 0.77 & 0.87 & - & - \\
\hline Muscovite & 2.94 & - & - & - \\
\hline Dolomite & - & 1.26 & - & 0.55 \\
\hline Calcite & - & 0.52 & - & 20.35 \\
\hline Albite & - & - & - & 32.72 \\
\hline Microcline & - & - & - & 4.67 \\
\hline Biotite & - & - & - & 0.55 \\
\hline Calcite & - & - & 100 & 100.55 \\
\hline Total & 100 & 99.99 & & - \\
\hline
\end{tabular}


Table 3: Sieve Size Analysis of Processed Materials.

\begin{tabular}{|c|c|c|c|c|c|c|c|c|c|c|c|c|}
\hline \multirow[b]{2}{*}{$\begin{array}{c}\text { Mesh Size } \\
\text { Diameter } \\
\quad(\mu \mathrm{m})\end{array}$} & \multicolumn{3}{|c|}{ Kaolin } & \multicolumn{3}{|c|}{ Feldspar } & \multicolumn{3}{|c|}{ Silica } & \multicolumn{3}{|c|}{ Clay } \\
\hline & 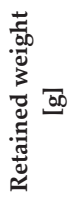 & 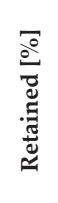 & 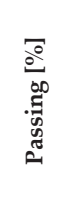 & 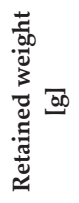 & 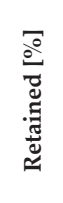 & 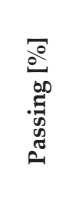 & 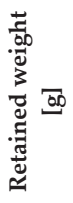 & 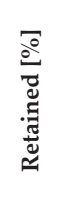 & 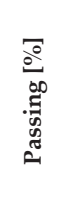 & 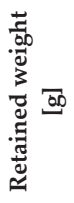 & 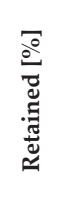 & 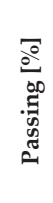 \\
\hline 236 & 0.0 & 0.0 & 100.0 & 0.0 & 0.0 & 100.0 & 0.0 & 0.0 & 100.0 & 3.9 & 1.6 & 98.4 \\
\hline 118 & 16.0 & 6.4 & 93.6 & 0.6 & 0.2 & 99.8 & 0.0 & 0.0 & 100.0 & 30.5 & 12.2 & 87.8 \\
\hline 85 & 1.1 & 0.4 & 93.2 & 1.1 & 0.4 & 99.3 & 0.2 & 0.1 & 99.9 & 1.0 & 0.4 & 87.4 \\
\hline 60 & 76.9 & 30.8 & 62.4 & 1.2 & 0.5 & 98.8 & 0.5 & 0.2 & 99.7 & 85.0 & 34.0 & 53.4 \\
\hline 42.5 & 69.1 & 27.6 & 34.8 & 1.0 & 1.9 & 98.4 & 0.2 & 0.1 & 99.6 & 71.7 & 28.7 & 24.7 \\
\hline 30 & 44.0 & 17.6 & 17.2 & 4.8 & 12.5 & 96.5 & 0.2 & 0.1 & 99.6 & 28.1 & 11.2 & 13.5 \\
\hline 15 & 38.4 & 15.4 & 1.8 & 31.2 & 53.7 & 84.0 & 74.4 & 29.8 & 69.8 & 23.1 & 9.2 & 4.2 \\
\hline 6.3 & 3.9 & 1.6 & 0.2 & 134.2 & 30.4 & 30.4 & 168.7 & 67.5 & 2.3 & 4.1 & 1.6 & 2.6 \\
\hline$<6.3$ & 0.6 & 0.2 & 0.0 & 75.9 & 0.0 & 0.0 & 5.8 & 2.3 & 0.0 & 2.6 & 1.0 & 0.0 \\
\hline Sum & 250 & 100 & & 250 & 99.6 & & 250 & 99.9 & & 250 & 99.9 & \\
\hline $\begin{array}{c}\text { Initial } \\
\text { weight }(\mathrm{g})\end{array}$ & & & & & & & & & & & & \\
\hline
\end{tabular}

Table 4: Adopted Porcelain Body Compositions [5][29]

\begin{tabular}{cccccc}
\hline Material & Kaolin & Ball Clay & Feldspar & Silica & Total \\
\hline Body sample composition [\%] & 33 & 15 & 32 & 20 & 100 \\
\hline
\end{tabular}

compositions from selected past research as shown on table 4. Selected composition has been deemed suitable for production of electrical porcelain insulator, given that the current study is not hinged on developing body composition, but aims at examining the effect of particle sizes on the dielectric and mechanical strengths of electrical porcelain insulator using locally available materials.

In the formation of test Samples using Press Cast technique, a pressure gauge of $100 \mathrm{MPa}$ was fabricated on a $5 \mathrm{~kg}$ hydraulic press jack in order to measure the pressure applied in moulding the samples. This ensures that samples are equally treated. A batch composition of $1 \mathrm{~kg}$ of the processed materials was weighed and passed through magnetic sieve in order to remove appreciable amount of iron oxide present in the materials. A Solvent of $15 \%$ comprising of water and sodium silicate in the ratio 49:1 was thoroughly mixed with $1000 \mathrm{~g}(1 \mathrm{~kg})$ mass of the batch composition. $65 \mathrm{~g}$ of each sample composition was measured, compacted and pressed at 500 Psi (3.4 KN) into a steel cylindrical mould using the hydraulic press, to yield cylindrical samples approximately $25 \mathrm{~mm}$ diameter and $35 \mathrm{~mm}$ height.

Five replicates of each sample composition were produced and the samples were left to dry in air for $24 \mathrm{hrs}$, before been kept air tight for another 15 days until firing. Each constituent sample of formulated Porcelain body press cast was heat treated at $1200^{\circ} \mathrm{C}$ and soaked for 30 minutes after attaining the temperature, so that heat is evenly distributed within the sample in the kiln.

\subsection{Measurement and Observation}

Shrinkage test was conducted on the samples produced by taking length, diameter (using Vernier calliper) and weight prior to firing at $1200^{\circ} \mathrm{C}$. The samples were allowed to cool down at room temperature; thereafter, measurements were

Shrinkage $=\frac{\text { Drylength }- \text { Fired length }}{\text { Drylength }} \times 100$

repeated. Difference in dry and fired lengths as a percentage of the value of dry length is computed using;

Bulk density $=\frac{\text { Dryweight }}{\text { Volume }}$

Bulk density of the samples in grams per cubic centimetre was also expressed as the quotient of its dry weight (D) according to the expression;

Note: Volume is weight (mass) of the water absorbed specimen from weight (mass) of suspended specimen in water.

Computation of equations (1), and (2) follow 
the ASTM C20-00 standards. In addition, Insulation volume resistivity of the samples were tested using $1 \mathrm{kV}$ Megger insulation tester (Avoc Megger model BM80/2) using direct current (D.C) voltage. This is done by injecting $1.5 \mathrm{kV}$ into the samples. The two terminals; cathode and anode are placed at both ends of each sample, and the current readings on the test kit taken at the second blink of the insulation tester. Dielectric strength of the samples was also determined by injecting $15 \mathrm{kV}$ into the samples using Hipotronic tester (15Kv Dielectric Test set CAT. NO 220015 series) using an alternating current (A.C) voltage. Phase transformation of fired samples were determined by X-ray diffraction using PANalytical Empyrean diffractometer with PIXcel detector and fixed slits with Fe filtered Co-Ka radiation, with the phases identified using X'PertHighscore plus software. Relative phase amounts (weights $\%)$ were weighed using the Rietveld method. The mechanical strength test was also determined using an automatic digital readout machine.

\section{Results and Discussion}

\subsection{Shrinkage and Bulk Density Analysis}

Results of shrinkage and bulk density analysis according to ASTM C20-00 standards are as shown on Table 6. The Table 5 reveals that all the samples yielded low shrinkage values due to the fact that the smaller particle sized materials act as fillers, thus, reducing the pore in the composition. This is in qualitative agreement with the result of Olupot et al. [29]. Shrinkage increases with particle size, and this determines the pores in a sample. Porcelain insulator sample with $300 \mu \mathrm{m}$ particle size has the highest shrinkage value of $1.42 \%$, followed by 150 $\mu \mathrm{m}$ particle size with $0.80 \%$ and $75 \mu \mathrm{m}$ particle which has the least shrinkage value of $0.41 \%$. These results indicate that the particle sizes can impact on Porcelain material shrinkage. This is also in line with the findings of [30]; which noted that when porosity of a sample decreases, it tends to increase the density of the sample. Bulk density across all particles is almost at par, even though the $150 \mu \mathrm{m}$ particle size has the highest bulk density value of $2.35 \mathrm{~g} / \mathrm{cm} 3$; this is due to the fact that the highest particle size i.e. $300 \mu \mathrm{m}$ also contains different particles sizes that are lesser but not more than $300 \mu \mathrm{m}$. This can also be seen in table 4 that the bulk of particle sizes in the material used are within $6.3 \mu \mathrm{m}$ and $60 \mu \mathrm{m}$. Also, particle size, as well as its distribution determine how particles are pack together, which will invariably affect the bulk density of sample produced.

Table 5: Shrinkage and Bulk density of Porcelain Insulator produced from different Particulate sizes.

\begin{tabular}{cccc}
\hline \multirow{2}{*}{ Parameter } & \multicolumn{3}{c}{ Particulate size } \\
\cline { 2 - 4 } & $\mathbf{7 5} \boldsymbol{\mu m}$ & $\mathbf{1 5 0} \boldsymbol{\mu m}$ & $\mathbf{3 0 0} \boldsymbol{\mu m}$ \\
\hline Shrinkage [\%] & 0.41 & 0.80 & 1.42 \\
\hline Bulk density $\left[\mathrm{g} / \mathrm{cm}^{3}\right]$ & 2.26 & 2.35 & 2.33 \\
\hline
\end{tabular}

This result implies that bulk density is a function of particle size and the shape distribution of materials compacted together. From Table 5, it shows that shape distribution of particle sizes in 150 $\mu \mathrm{m}$ favours its bulk density.

\subsection{Resistivity and Dielectric Strength analysis}

The voltage and the corresponding resistance at which produced Porcelain samples demonstrate discontinuity at the injection of $1 \mathrm{kV}$ is shown in Table 6 . The resistance of samples in the current study is in agreement with those reported by [22] whose results were in the range of $104 \Omega$-m to 1018 $\Omega-m$. Furthermore, dielectric strength of the forming techniques in this study is within the range of 6 $9 \mathrm{kV} / \mathrm{mm}$ at different particle sizes, which are still within the range of good dielectric properties [9]. Nevertheless, the results imply that the insulation resistance and the dielectric strength of the sample depreciate when the particle size is greater or less than $150 \mu \mathrm{m}$. Thus, $150 \mu \mathrm{m}$ particle size gives better insulation resistance and the dielectric strength in production of electrical Porcelain insulator.

Table 6: Resistivity $(\Omega-\mathrm{m})$ and Dielectric Strength $(\mathrm{kV} / \mathrm{mm})$ of Porcelain Insulator at different Particulate sizes.

\begin{tabular}{cccc}
\hline \multirow{2}{*}{ Parameter } & \multicolumn{3}{c}{ Particulate size } \\
\cline { 2 - 4 } & $\mathbf{7 5} \boldsymbol{\mu \mathrm { m }}$ & $\mathbf{1 5 0} \boldsymbol{\mu \mathrm { m }}$ & $\mathbf{3 0 0} \boldsymbol{\mu \mathrm { m }}$ \\
\hline Resistivity $(\boldsymbol{\Omega}-\mathbf{m}) \times \mathbf{1 0}^{\mathbf{1 4}}$ & 1.52 & 2.92 & 1.47 \\
\hline Dielectric Strength $(\mathbf{k V} / \mathbf{m m})$ & 7.8 & 9.0 & 7.7 \\
\hline
\end{tabular}

The resistivity and dielectric strength of Porcelain Insulator samples with different particle sizes; the Figure 1 better clarifies how the different particle size of materials used in the design of Porcelain insulators relate to bulk density and shrinkage respectively. This result implies that the bulk density of the materials used is dependent on temperature and not on the particle sizes of the material used. This is so because, as the temperature increases, the material become fluidic and thus seal up the pores in between the Porcelain material constituents. 


\subsection{Microstructure}

Figures 1-3 show sample microstructures sintered at $1200^{\circ} \mathrm{C}$. Phase morphology and chemical analysis made it possible to identify morphology and elemental composition using Scanning Electron Microscopy (SEM) (Figures 1a, 2a, and 3a), and Energy Dispersive X-Ray Spectroscopy (EDS) (Figures 1b, 2b, and $3 \mathrm{~b}$ ) analysis. In Figures 1a, 2a, and 3a, a vitreous phase was formed, indicating similar evidence of quartz and mullite crystals in all the samples. Figures $1 b, 2 b$, and $3 b$ show alumina and silica in the presence of oxygen which are responsible for the formation of quartz and mullite phases at high firing temperature. While the mechanical properties of Porcelain insulator have been elucidated as the effect of these phases, they are also responsible for matrix reinforcement and dispersion strength of triaxle Porcelain.
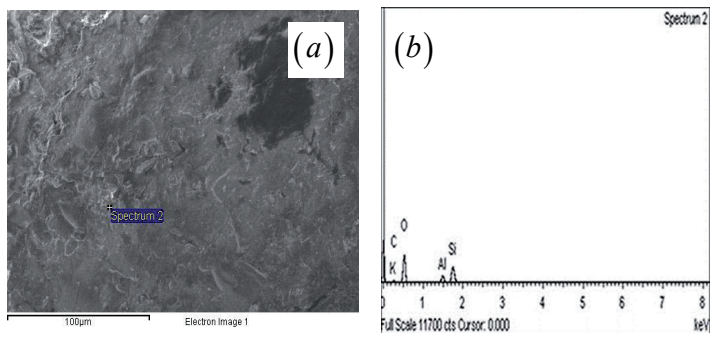

Figure 1: (a) SEM Micrograph of $75 \mu \mathrm{m}$ particle size; (b) EDS pattern for $75 \mu \mathrm{m}$ particle size.
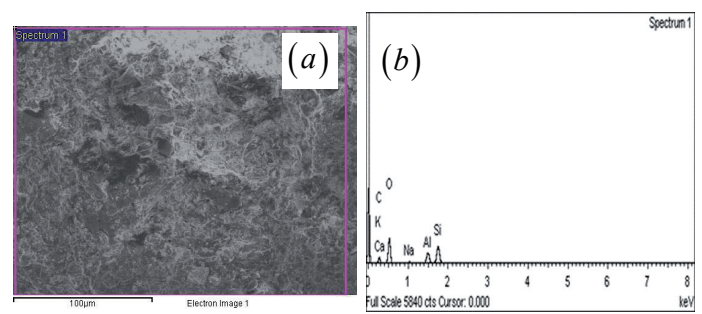

Figure 2: (a) SEM Micrograph of $150 \mu \mathrm{m}$ particle size; (b) EDS pattern for $150 \mu \mathrm{m}$ particle size.
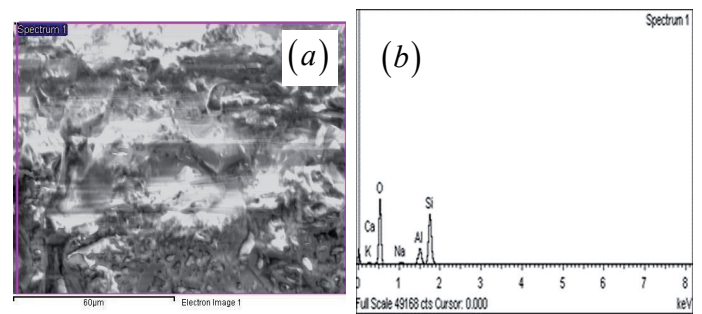

Figure 3: (a) SEM Micrograph of $300 \mu \mathrm{m}$ particle size; (b) EDS pattern for $300 \mu \mathrm{m}$ particle size.
Moreover, pores are evidently visible in Figures $1 \mathrm{a}, 2 \mathrm{a}$, and $3 \mathrm{a}$, although, Figure $1 \mathrm{a}$ is highly agglomerated. This further affirms the result of shrinkage test conducted on the sample that 75 $\mu \mathrm{m}$ has low shrinkage since the particle are largely compacted. Particle size $150 \mu \mathrm{m}$ (B2P) has lesser amount of $\mathrm{Al}$, Si and $\mathrm{K}$ in comparison to particle size $300 \mu \mathrm{m}$ (B3P) as revealed by the EDS results in Figure 4. The implication of this is that the $150 \mu \mathrm{m}$ particle size shows the presence of more mullite, which contributes to matrix reinforcement and dispersion strength of triaxle porcelain. This also results in peak value observed in insulation volume resistivity and the dielectric strength of Porcelain insulator produced from different $150 \mu \mathrm{m}$ particulate size. The comparison of the insulating behaviour in relation to particle size is crucial for modern day use of Porcelain in transmission lines.

Results obtained from this study has so far shown that the combined porosity of the component materials of Porcelain (Clay, Silica, Kaolin, and Feldspar) designed within this study increases with simultaneous increase in the size of sand grains adopted in the design of the material. Furthermore, the bulk density of the materials after compaction decreases with increase in particle size and vice versa. Lastly, $150 \mu \mathrm{m}$ particles of the component materials produces better porcelains insulator than either of the $75 \mu \mathrm{m}$ of the $300 \mu \mathrm{m}$ particle sizes. This result is confirmed from the insulation volume resistivity and dielectric strength generated by the $150 \mu \mathrm{m}$, indicating the possibility of lowering the insulation volume resistivity and dielectric strength when other particle sizes are utilized for production of porcelain insulator.

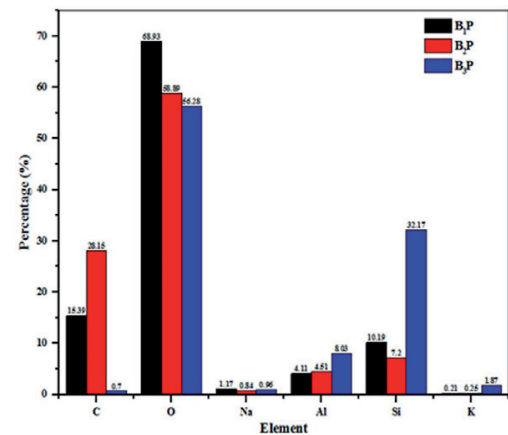

Figure 4: Comparative graphical representation of EDS analysis.

\section{Conclusion}

Results of this investigation on the mineralogical 
composition of Porcelain raw materials gathered from Aforwa and Okpella in Edo State, Nigeria showed that the materials at these locations are quite suitable for the production of electrical Porcelain insulators. Particle size analysis conducted proved that the bulk of the raw materials sourced from the site were within sand particulate classification. Further disaggregation of the sand particulate into fine, medium and course particulates indicate that medium particulate $(150 \mu \mathrm{m})$ produced best result for Porcelain insulators. Porosity and bulk density of the composition increases with particle size. Particle size, as well as its distribution determine how particles are pack together, which will invariably affect the bulk density of sample produced. Crystalline formation of mullite and particles size distribution are also considered as basic factors that contribute to production of high strength electrical porcelain insulator. Particle size and consistency of the properties of the starting powders is a very critical requirement to achieving high voltage insulators at low cost and saves time. The higher the surface area of the starting powder, the more heat is needed to make the materials fluidic to seal up the pores. It is much better to consider the particle size of the starting powder as it also affects the cost of production of porcelain. Moreover, this study confirmed that $150 \mu \mathrm{m}$ particle size produced the best insulation volume resistivity as well as dielectric strength, while particle sizes greater or less than this value decreases insulation resistivity and dielectric strength values. Thus, the ceramic raw materials processing at $150 \mathrm{\mu m}$ particle for electrical porcelain insulator improves the insulation resistance as well as the dielectric strength properties useful for effective electrical insulation applications.

As a research step in the right direction, future studies in Porcelain manufacturing should look to confirm the results within this study using materials sourced from other locations. Furthermore, given the wide spread usage of Porcelain materials as some of the commonest insulating materials around, it is important that research continues to look at ways of further optimizing these materials, especially in relation to some of its observed weaknesses as reported in literature.

\section{Acknowledgments}

The authors wish to acknowledge the financial support provided by the management of the Federal University of Technology
(FUTA), Akure, Nigeria during the course of this research work. The work is partially supported by the SPEV project, University of Hradec Kralove, FIM, Czech Republic (ID: 2103-2021), "Smart Solutions in Ubiquitous Computing Environments", Faculty of Informatics and Management, University of Hradec Kralove, Czech Republic EU. We are also grateful for the support of Ph.D. candidate Sebastien Mambou in image processing techniques.

\section{References}

1. Bengisu, M. (2001) Structure and Properties of Conventional Ceramics, Engineering Ceramics, M. Bengisu, Ed. Berlin, Heidelberg: Springer, pp. 447-466.

2. Cordier, P. (2004) Dislocations in Minerals," in Encyclopedia of Materials: Science and Technology, K. H. J. Buschow, R. W. Cahn, M. C. Flemings, B. Ilschner, E. J. Kramer, S. Mahajan, and P. Veyssière, Eds. Oxford: Elsevier, 2004, pp. 1-13

3. Brown, G. E., Trainor, T. P., Chaka, A. M. (2008) Geochemistry of Mineral Surfaces and Factors Affecting Their Chemical Reactivity, Chemical Bonding at Surfaces and Interfaces, A. Nilsson, L. G. M. Pettersson, and J. K. Nørskov, Eds. Amsterdam: Elsevier, 2008, pp. 457-509.

4. Berner, R. A., Lasaga, A. C., Garrels, R. M. (1983) The carbonatesilicate geochemical cycle and its effect on atmospheric carbon dioxide over the past 100 million years, Am J Sci, vol. 283, no. 7, pp. 641-683, doi: 10.2475/ajs.283.7.641

5. Merga, A., Murthy, H. C. A., Amare, E., Ahmed, K., Bekele, E. (2019) Fabrication of electrical porcelain insulator from ceramic raw materials of Oromia region, Ethiopia, Heliyon, vol. 5, no. 8, doi: 10.1016/j.heliyon.2019.e02327.

6. Bundy, W. M. Ishley, J. N. (1991) Kaolin in paper filling and coating, Applied Clay Science, vol. 5, no. 5, pp. 397-420, doi: 10.1016/0169-1317(91)90015-2.

7. Kobe, K. (1950) Kaolin clays and their industrial uses, Journal of Chemical Education, vol. 27, no. 2`', p. 111, doi: https://doi. org/10.1021/ed027p111.1

8. Pass, J., Seymour, A. P. (1892) Porcelain insulator, US476813A

9. Nasejje, S., Sam, O. K. (2015) Dependency of Dielectric Strength of Kaolin on Processing Method, Journal of Scientific Research and Reports, pp. 306-312, doi: 10.9734/ JSRR/2015/13335.

10. Tod, J. H. (1977) A History of Electrical Porcelain Industry in the United States. Phoenix, Arizona: Jack H. Tod,

11. Sachidananda,D.(2019)TypesofInsulators,ElectricalShouters, https://electricalshouters.com/types-of-insulators/ (accessed Nov. 02, 2019).

12. Electric Mastar, (2017) Types of insulator, Electrical mastar, http://www.electricalmastar.com/insulator-typesinsulator/ (accessed Nov. 03, 2019).

13. Ashika, R., (2017) Insulators Used for Overhead Transmission Lines, Engineering Notes India, http://www. 
engineeringenotes.com/electrical-engineering/insulators/ insulators-used-for-overhead-transmission-lines-5-typeselectricity/29129 (accessed Nov. 03, 2019).

14. GreenSpec (2019) Insulation materials and their thermal properties, Green Building Design,. http://www.greenspec. co.uk/building-design/insulation-materials-thermalproperties/ (accessed Nov. 04, 2019).

15. Gorur, R. S., (2005) High-Voltage Transmission, The Electrical Engineering Handbook, pp. 737-748, doi: 10.1016/B978012170960-0/50054-2.

16. Electric 4 u (2019) Types of Insulators in Transmission Lines|Electrical4u, https://www.electrical4u.com/, https:// www.electrical4u.com/types-of-electrical-insulatoroverhead-insulator/ (accessed Nov. 03, 2019).

17. Islam, R. A., Chan, Y. C., Islam, Md. F. (2004) Structure-property relationship in high-tension ceramic insulator fired at high temperature, Materials Science and Engineering: B, vol. 106, no. 2, pp. 132-140, doi: 10.1016/j.mseb.2003.09.005.

18. McGlinchey, D. (2016) Sampling and Characterization of Bulk Particulate Materials and Products, Production, Handling and Characterization of Particulate Materials, H. G. Merkus and G. M. H. Meesters, Eds. Cham: Springer International Publishing, pp. 515-545.

19. Berry, B. (1995) A Brief History of Porcelain Insulators, Insulators Info, https://www.insulators.info/porcelain/ history.htm (accessed Oct. 31, 2019).

20. Berry, B. (2003) Porcelain Insulator Collectors Reference Site, Insulators Info, https://www.insulators.info/porcelain/ (accessed Oct. 31, 2019).

21. Nature (1942) Porcelain Insulators, Nature, pp. 19-20, doi: doi:10.1038/150019c0.

22. Thompson, W. G. (1944) The mechanism of the contamination of porcelain insulators, Journal of the Institution of Electrical Engineers - Part Il: Power Engineering, vol. 91, no. 22, pp. 317-327, doi: 10.1049/ji-2.1944.0045.

23. Luo, L. et al. (2014) Research on the electrolytic corrosion problem of porcelain insulator's hardware on UHVDC transmission line, 2014 IEEE Electrical Insulation Conference (EIC), pp. 97-101, doi: 10.1109/EIC.2014.6869355.

24. McAfee, R. D., Heaton, R. D., King, J. M., Falster, A. U. (1997) A study of biological contaminants on high voltage porcelain insulators, I," Electric Power Systems Research, vol. 42, no. 1, pp. 35-39, doi: 10.1016/S0378-7796(96)01174-1.

25. Sanyal, S. et al. (2019) Deterioration of Porcelain Insulators Utilized in Overhead Transmission Lines: A Review, Trans. Electr. Electron. Mater., doi: 10.1007/s42341-019-00143-5.

26. Steico (2019) Product overview, Steico, https://www.steico. com/en/products/overview/ (accessed Nov. 04, 2019).

27. Warmcel (2019) Cellulose Fibre Insulation, Insulation for Timber Frame, Warmcel, https://www.warmcel.co.uk/ (accessed Nov. 04, 2019).

28. Thermafleece (2019) British Sheep's wool insulation, Thermafleece, https://www.thermafleece.com/ (accessed Nov. 04, 2019).

29. Olupot, P. W., Jonsson, S., Byaruhanga, J. K. (2010) Development and characterisation of triaxial electrical porcelains from Ugandan ceramic minerals, Ceramics International, vol. 36, no. 4, pp. 1455-1461, doi: 10.1016/j. ceramint.2010.02.006.

30. Mohammad, N. F., Kanesvaran, G., Othman, S. M., Mohammad, I. S. (2012) Effect of particulate size on mechanical strength of Anadara granosa bioceramic, 2012 International Conference on Biomedical Engineering (ICoBE), Penang, Malaysia, pp. 104-108, doi: 10.1109/ ICOBE.2012.6178964 